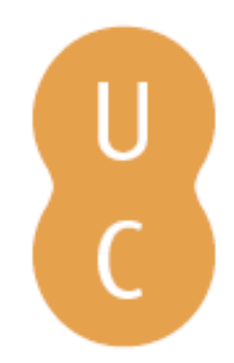

\title{
nommalina
}

\section{Ambientes aquáticos não marítimos no baixo Mondego: margens para a recreação, 0 lazer e o turismo}

\author{
Autor(es): $\quad$ Moreira, Claudete Oliveira \\ Publicado por: Imprensa da Universidade de Coimbra \\ URL \\ persistente: URI:http://hdl.handle.net/10316.2/30768 \\ DOI: $\quad$ DOI:http://dx.doi.org/10.14195/978-989-26-0244-8_15 \\ Accessed : $\quad$ 26-Apr-2023 06:45:00
}

A navegação consulta e descarregamento dos títulos inseridos nas Bibliotecas Digitais UC Digitalis, UC Pombalina e UC Impactum, pressupõem a aceitação plena e sem reservas dos Termos e Condições de Uso destas Bibliotecas Digitais, disponíveis em https://digitalis.uc.pt/pt-pt/termos.

Conforme exposto nos referidos Termos e Condições de Uso, o descarregamento de títulos de acesso restrito requer uma licença válida de autorização devendo o utilizador aceder ao(s) documento(s) a partir de um endereço de IP da instituição detentora da supramencionada licença.

Ao utilizador é apenas permitido o descarregamento para uso pessoal, pelo que o emprego do(s) título(s) descarregado(s) para outro fim, designadamente comercial, carece de autorização do respetivo autor ou editor da obra.

Na medida em que todas as obras da UC Digitalis se encontram protegidas pelo Código do Direito de Autor e Direitos Conexos e demais legislação aplicável, toda a cópia, parcial ou total, deste documento, nos casos em que é legalmente admitida, deverá conter ou fazer-se acompanhar por este aviso.

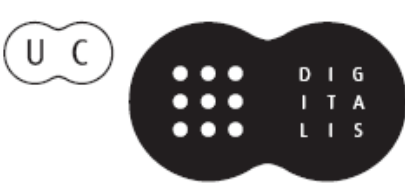




\section{TRUNFOS DE UMA}

\section{EOGRAFIA ACIVA}

\section{DESENVOLVIMENTO LOCAL,}

AMBIENTE,

ORDENAMENTO

E TECNOLOGIA

Norberto Santos

Lúcio Cunha

COORDENAÇÃO 
Claudete Oliveira Moreira

Centro de Estudos de Geografia e Ordenamento do Território - CEGOT

Universidade de Coimbra

\section{AMBIENTES AQUÁTICOS NÃO MARÍTIMOS NO BAIXO MONDEGO: MARGENS PARA A RECREAÇÃO, O LAZER E O TURISMO}

\section{AMBIENTES AQUÁTICOS: MARGENS PARA A RECREAÇÃO, O LAZER E O TURISMO}

A hidrolatria, traduzida pelo desejo de proximidade de planos de água naturais e/ou artificiais: oceanos, mares, canais, lagos, lagoas, rios, albufeiras, é intemporal. Numa tipologia bipartida os ambientes aquáticos podem ser classificados como marítimos e não marítimos, ainda que na confluência de ambos se encontrem ambientes aquáticos cuja hidrodinâmica é mareal e fluvial, designadamente os estuários.

Entre os ambientes aquáticos não marítimos merecem especial relevo as linhas de água pois suportam, hoje, como ontem, muitas das actividades humanas. O próprio curso evolutivo das sociedades humanas está intimamente ligado aos cursos de água. Os rios desempenharam sempre uma função relevante em todas as civilizaçóes; estando estreitamente ligados à sociedade que suportam e às comunidades que a ele se ligam (Mauch; Zeller, 2008). Se transversalmente os rios dividem eles são também um elemento de ligação multissecular, principalmente quando perspectivados em termos de via de comunicação e de circulação de pessoas e de bens, animando a vida económica e social das áreas ribeirinhas. $\mathrm{Na}$ sociedade actual, pós-moderna ou da modernidade tardia, centrada no tempo livre, no consumo, no lazer e no turismo, as frentes de água e as margens dos rios adquirem novas ocupaçóes por parte, muitas das vezes, daquelas funçóes caracteristicamente urbanas que se haviam afastado das margens: residencial, comercial e recreativa. Os rios, hoje, juntamente com outros ambientes aquáticos, servem de recurso-suporte, designadamente na criação de oportunidades de prestação de serviços que se ligam com o tempo livre outdoor e com a criação de produtos turísticos.

Em algumas regióes os rios são importantes elementos espaciais da paisagem cultural urbana enquanto recurso turístico significante (Prideaux et al., 2009), atribuindo uma ambiência muito própria a algumas cidades e vilas. Elementos naturais que justificaram o sítio de implantação original de muitos núcleos urbanos os rios assim como os espelhos de água são, cada vez mais, integrados no espaço construído, valorizados como espaço público e utilizados como lugares de recreio: «nas últimas décadas as linhas de água tornaram-se os lugares mais proeminentes para a recreação e para as actividades de lazer» (Erfurt-Cooper, 2009: 95).

As margens são territórios de ordenamento por excelência, constroem-se parques lineares, pontuam-se as frentes de água com novos investimentos, promovem-se comércios e 
serviços, procura-se não só compatibilizar os antigos usos como recriar usos mais sustentáveis. Criam-se espaços abertos que unificam a cidade e os planos de água, ampliam-se os espaços urbanos de uso público, tornando as margens, designadamente dos rios, paisagens atractivas para actividades recreativas, lúdicas e desportivas.

As linhas de água têm sido objecto de várias intervenções (Saraiva, 1999; Breil et al., 2008), integrado estratégias de regeneraçáo urbana que têm permitido às autoridades locais a reconstrução das cidades. O planeamento urbano na Europa das décadas de 80 e de 90 do século XX ficou marcado por estratégias de regeneração das margens dos rios que estavam abandonadas e de valorização das frentes de água (Jones, 2007). Em muitas cidades da Europa as margens dos rios são localizaçóes preferenciais para hotéis e restaurantes, proporcionado aos consumidores vistas panorâmicas e espaços agradáveis e relaxantes (Erfurt-Cooper, 2009; Williams, 2009), integrando-se o processo de regeneração das frentes de água na transformação pós-industrial/pós-moderna de refazer as cidades e a sua identidade (Marshall, 2001; Williams, 2009), o que denota a importância de ao nível da paisagem urbana integrar os ecossistemas aquáticos naturais nos espaços construídos (Day et al., 2008).

Em Portugal o Programa Polis, Programa de Requalificação Urbana e Valorização Ambiental de Cidades, criado em 2000 e integrado no III Quadro Comunitário de Apoio, ao procurar replicar pelo território nacional a experiência organizacional e urbanística do EXPO'98, permitiu valorizar frentes de mar e de rio. As margens de vários rios foram transformadas em espaço público, constituindo-se como corredores pedonais e/ou cicláveis, refiram-se as do Rio Tâmega, em Chaves; do Rio Lima, em Viana do Castelo; do Rio Mondego, em Coimbra; do Rio Lis, em Leiria; do Rio Tejo em Vila Franca de Xira, como casos paradigmáticos; promoveram-se assim espaços públicos para o lazer casual. Os investimentos em equipamentos e infra-estruturas de lazer, na cultura e nas artes, permitiram atrair eventos, instituiçóes, empresas, negócios, investidores e turistas e constituíram-se como um factor de competitividade das cidades, ao permitirem melhorar a paisagem e a imagem das urbes. Todavia as linhas de água estendem-se muito para além dos limites da cidade, cruzando paisagens diversas, periurbanas e rurais, montanhas, planaltos e planícies, enquanto conectam cidades. O seu potencial não é negligenciável para o lazer e o turismo de actividades outdoor. Revela-se pois essencial articular as motivaçóes e experiências das margens entre si e estas com o percurso dos rios.

$\mathrm{Na}$ contemporaneidade «o lazer tornou-se no primado da fuga à rotina, através da valorização do prazer, do hedonismo, da aventura e das actividades radicais» (Santos \& Gama, 2008: 16), há um interesse por parte da população em procurar novas experiências sensoriais, em ter um contacto com as paisagens, com o natural, com o cultural, fazendo mesmo parte esta procura - touring cultural e paisagístico, turismo activo -, de um certo lifestyle. Um estilo de vida em que se promove, para além do contacto com a natureza, a aventura, aliada, frequentemente, à prática de actividades desportivas, onde é notório o interesse reinventado pelos ambientes aquáticos não marítimos.

A água proporciona experiências multissensoriais. Sáo os passeios curtos de barco ou os cruzeiros, a pesca desportiva e de lazer, as actividades náuticas como a canoagem, o canyoning, o rafting, o hidrospeed, entre outras, que se integram no turismo aventura e que se combinam com o turismo natureza e com o ecoturismo. Jennings (2007), entende o turismo aventura como um turismo de nicho considerando que no início do século XXI cresce o leque de opçóes em termos de experiências de recreação que contemplam activi- 
dades desportivas e que envolvem os ambientes aquáticos, que vão do fácil ao extremamente exigente, de uma realização individual a uma realizaçáo em equipa, de uma participação casual a uma participação organizada, de equipamentos simples até equipamentos sofisticados, de custos de participação irrisórios até custos muito elevados. De acordo com Inskeep (1991) o turismo aventura integra formas especializadas de turismo, envolve um certo perigo, que pode ser real ou apenas percebido, através de desafios que são propostos aos turistas (outras características do turismo são apresentadas por Williams, 2009 e por Swarbrooke et al., 2003), é fundamentalmente um turismo outdoor, praticado em espaços abertos e mais ou menos recônditos, que náo requer grandes investimentos em infraestruturas e equipamentos pelo que se ajusta bem a áreas menos desenvolvidas e que não pretendem desenvolver um turismo de massas, mas que levam a que os turistas dispendam algum dinheiro para a prática destas actividades.

Em Portugal os ambientes aquáticos marítimos e não marítimos, mas especialmente entre estes últimos, os rios e as albufeiras, têm vindo a apresentar uma grande importância para as actividades de recreação, no âmbito quer do lazer quer do turismo outdoor integrando a oferta de actividades de turismo aventura.

\section{EMPRESAS DE ANIMAÇÃO TURÍSTICA EM PORTUGAL CONTINENTAL: A IMPORTÂNCIA DOS AMBIENTES AQUÁTICOS}

Uma análise do Registo Nacional dos Agentes de Animação Turística (RNAAT) permite concluir que em 2009 (Abril) havia 519 empresas de animação turística licenciadas a operar em Portugal. Destas empresas cerca de 48,4 \% (251) desenvolviam pelo menos uma actividade em meio aquático natural ou semi-natural (marítimo e/ou fluvial) e/ou artificial. É residual, e como tal pouco expressiva, a percentagem de empresas que se dedicam em exclusivo a estas actividades (5,6\%). Entre as empresas que promovem actividades em ambientes aquáticos cerca de $43 \%$ desenvolvem apenas uma actividade, sendo a mais frequente a canoagem, uma actividade que certamente por não requerer condiçóes naturais e técnicas muito específicas, como acontece com o canyoning ou com o rafting, para se referirem apenas dois exemplos. Estas empresas promovem, combinando, o lazer, a aventura e a água, e expressam-no bem nas designações que assumem. No caso da água oferecem-se caminhos d'água, quebra águas, down stream valorizam-se rios \& trilhos e as margens, principalmente para vários desportos sport margens mas também se oferecem alguns planos e cursos de água como nautialqueva, transguadiana, douro acima, turiarade, isto para apenas referir algumas das designaçóes destas empresas de animação turística.

O padrão espacial das empresas de animação turística que promovem actividades de lazer e de turismo em ambientes aquáticos (Fig. 1) evidencia um contínuo de oferta no litoral sul. É aqui e no sul da Costa Vicentina que se localizam as duas freguesias com um maior número de empresas, Aljezur e Albufeira. Para além disto, há nucleaçóes importantes, ainda que de dimensão variável, no litoral ocidental, em Setúbal, em Lisboa, em Cascais, em Peniche, na Figueira da Foz e no Porto, nestes casos mais voltadas para os ambientes aquáticos marítimos. Esta oferta de actividades em ambientes aquáticos não só pontua o litoral como se dispersa, claramente, para o interior, evidenciando uma forte ligação aos rios principais e seus tributários de referência, com destaque para as bacias hidrográficas dos rios Tejo, Mondego, Douro e Cávado. No território noroestino de Portugal a 
utilização dos planos de água das albufeiras de barragem junta-se à pujança da natureza que na montanha é expressiva para se constituir como motivo de lazer e turismo (Martins, 2004: 52). A oferta é mais ubíqua a norte do rio Tejo, estando a sul claramente interiorizada e adquirindo expressividade em torno do Grande Lago, proporcionado pela albufeira de barragem de Alqueva; aqui o turismo surge como o garante da viabilidade de um empreendimento idealizado no século XX, na segunda metade dos anos 50, integrado no plano de rega do Alentejo (Caldas, 2006). Estas actividades revestem-se de algum significado económico para as comunidades locais que as promovem e que vêem nos ambientes aquáticos de proximidade oportunidades de investimento. Combinando por vezes a oferta de actividades e de experiências em ambientes aquáticos com outras que estão em terra, nas margens, com uma acentuada componente natural e cultural local. A comprovar, precisamente, esta diversificação da oferta está o facto de apenas 10,7\% destas empresas actuarem exclusivamente em ambiente aquático.

Figura 1 - Empresas de animação turística que promovem actividades de lazer e de turismo em ambientes aquáticos, por freguesias, segundo as bacias hidrográficas, em Portugal Continental, em 2009. Fonte: Elaboração própria com base no RNAAT, Abril de 2009.

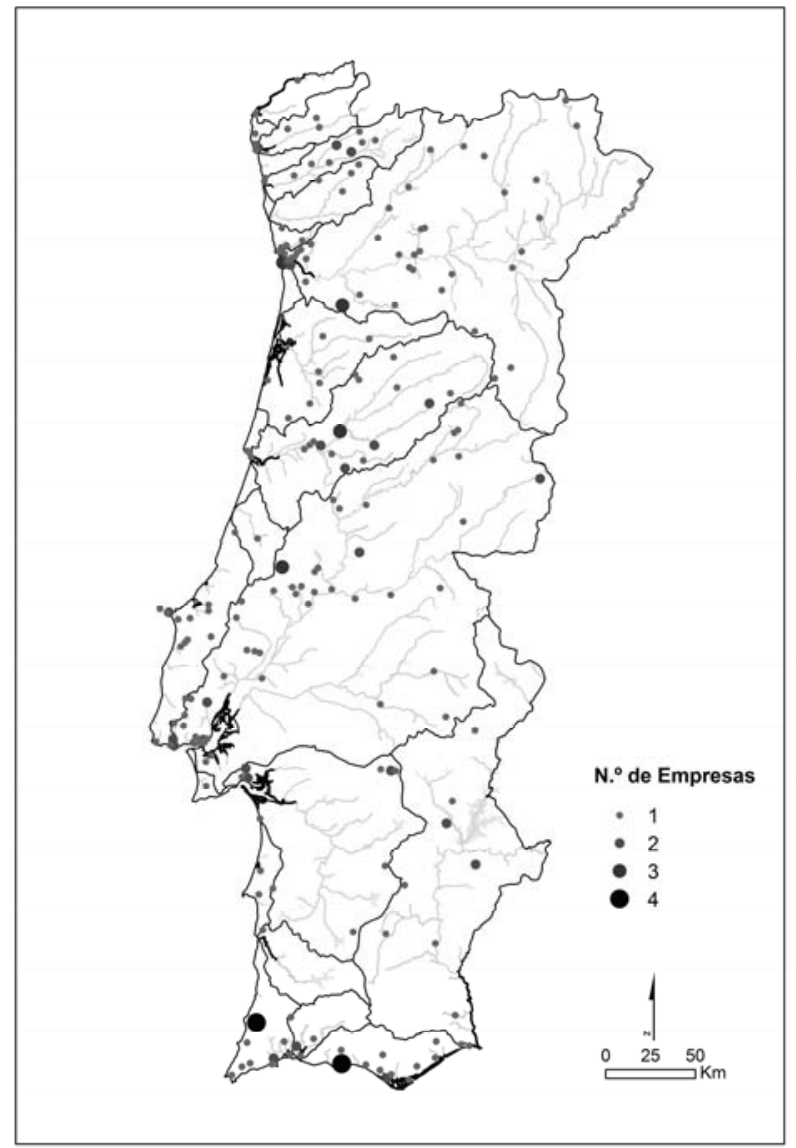


O Plano Estratégico Nacional do Turismo, PENT 2007, referencia o turismo náutico como um dos dez produtos estratégicos para o desenvolvimento do turismo em Portugal. As estações náuticas figuram como um dos produtos turísticos náuticos disponíveis, podendo constituir-se como um destino turístico de costa ou de interior. Apesar destas estaçóes náuticas serem quase sempre perspectivadas para ambientes aquáticos marítimos, é importante que o conceito se interiorize. Há concelhos do interior que beneficiando de características únicas, naturais e/ou artificialmente criadas, evidenciam já uma certa concentração da oferta, carecendo apenas de alguns investimentos e de uma maior densidade relacional entre os agentes locais públicos e privados. Deste modo é possível posicionar estes destinos e promovê-los através da organização de eventos desportivos de âmbito nacional e internacional ${ }^{1}$.

$\mathrm{Na}$ bacia hidrográfica do rio Mondego localizam-se 8,0\% das empresas de animação turística que promovem actividades em ambientes aquáticos, estas implantam-se preferencialmente em ambientes de montanha, em Penacova, mas também na Lousã, em Seia e em Arganil, nas proximidades dos rios Ceira e Alva, bem como na cidade de Coimbra e nas freguesias de Eiras, S. Martinho do Bispo e Taveiro e, mais a jusante, em S. Juliáo da Figueira da Foz e em Buarcos, esta última já fora da bacia hidrográfica.

O Baixo Mondego é claramente uma das sub-regiôes em que o rio dá significado aos territórios rurais e urbanos. O rio que secularmente rouba(va) terra às suas margens, converteu-se num eixo estruturante do povoamento e da socioeconomia no seu baixo vale, aquele que se desenvolve de Coimbra até à Figueira da Foz (Fig. 2). A navegaçáo fluvial que se fazia utilizando a barca serrana entre a foz e o porto da Raiva (Fig. 2) permitiu o crescimento de alguns lugares ribeirinhos, que perderam pujança económica e social com o surgimento do caminho-de-ferro e com o desenvolvimento dos eixos rodoviários, bem como com a correlativa alteração de uma socioeconomia de base primária, assente nos produtos do mar e do rio, mas também agrícolas e artesanais, para uma socioeconomia terciarizada. Aqui, no seu vale inferior, os ambientes aquáticos dominam claramente a paisagem apresentando um potencial em termos de lazer e de turismo.

\section{AMBIENTES AQUÁTICOS NÃO MARÍTIMOS NO BAIXO MONDEGO}

No Baixo Mondego podemos encontrar vários tipos de ambientes aquáticos não marítimos que, em função do nível de intervenção do ser humano, podem ser diferenciados através de uma tipologia classificativa tripartida: i) ambientes aquáticos naturais: trechos do rio Mondego e dos seus afluentes, as lagoas, os pauis e o estuário; ii) ambientes aquáticos semi-naturais: as represas como o açude-ponte de Coimbra, as valas de derivaçáo das águas das cheias e as praias fluviais; iii) ambientes aquáticos artificiais: a densa rede de drenagem e de enxugo construída para o aproveitamento agrícola do vale, as marinhas e as exploraçóes de aquacultura. Muitos destes recursos na área do Baixo Mondego possuem já alguma atractividade turística (Rebelo et al., 1990), mas estão muito polarizados, pouco

\footnotetext{
${ }^{1}$ Há concelhos no interior que apresentam um potencial não negligenciável neste âmbito, a título meramente de exemplo refira-se o caso das Terras de Bouro, de Arouca e de Penacova. À semelhança do Centro Nautico de Constância, na confluência do Rio Zêzere com o rio Tejo, ou do recente Centro Náutico de Reguengos de Monsaraz, na albufeira de Alqueva.
} 
articulados entre si e com o rio principal, carecendo este rio - e o seu território - de um projecto de valorização que promova as suas margens, à semelhança da valorização que tem sido feita no rio Tejo (Simóes \& Vale, 2002).

Figura 2 - Ambientes aquáticos não marítimos no Baixo Mondego

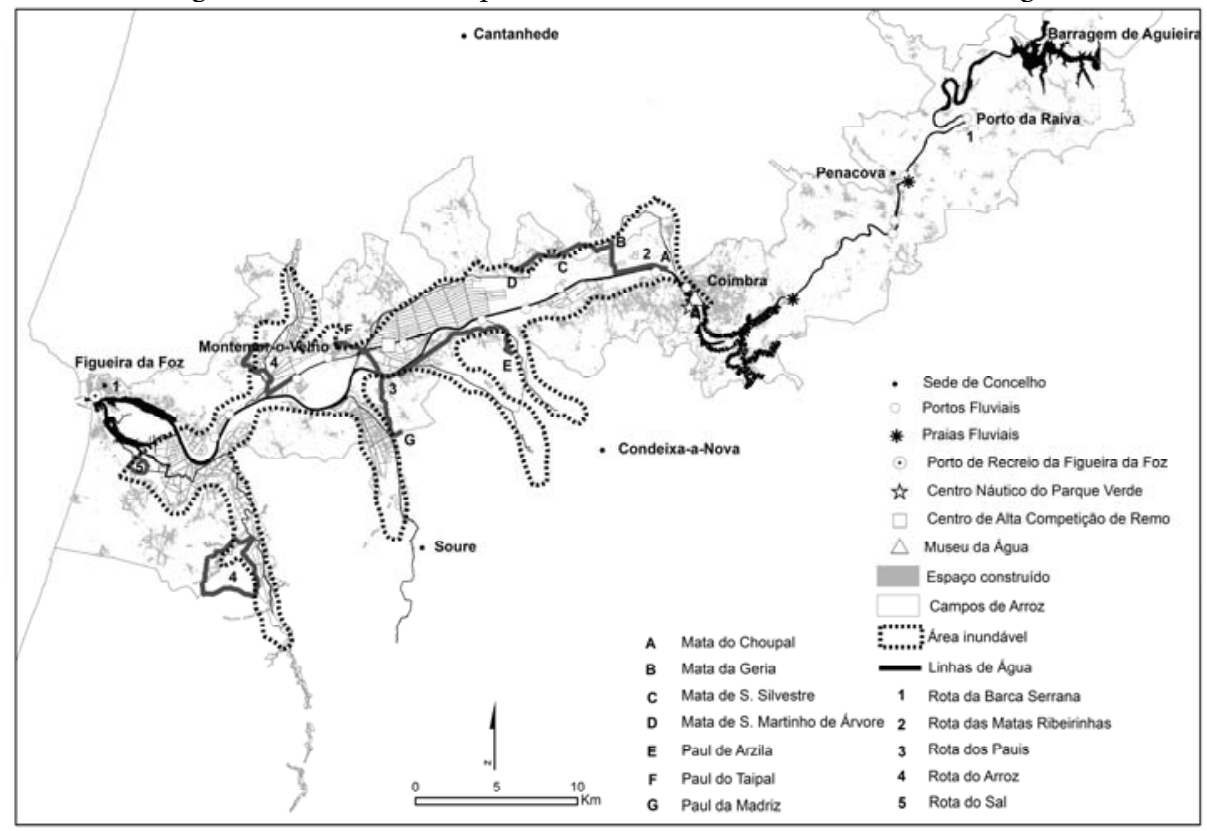

Dada a diversidade de ambientes aquáticos existentes e as restriçóes deste texto opta-se aqui por abordar apenas alguns. No baixo vale do Mondego foram muito frequentes os terrenos pantanosos, apaulados, alagados, também designados por alvercas e pauis, que testemunhavam bem as dificuldades de escoamento e o alteamento do leito do rio em relação aos campos marginais, condiçóes que favoreceram o cultivo do arroz. Hoje, persistem algumas destas zonas húmidas assumindo especial importância em termos de biodiversidade. A Reserva Natural do Paul de Arzila (Fig. 2), criada há 21 anos, é um bom exemplo de uma reserva que ocupa três municípios. Situa-se na margem esquerda do rio Mondego, está implantada na Ribeira de Cernache e é drenada por três valas. $\mathrm{Na}$ área alagada é possível encontrar bunho, caniço e tábua, já na área que faz a transição das valas encontra-se o lírio-amarelo, o choupo e o salgueiro. A par desta cobertura vegetal há uma grande diversidade de aves entre as quais se destacam a garça-vermelha e a garça-pequena. Uma outra área pantanosa é a Zona de Protecção Especial do Paul do Taipal (sítio Ramsar) (Fig. 2), esta área envolvida por pinhal têm um coberto vegetal dominado por caniço, com uma população de patos-trombeteiros que migram para este espaço nos meses de inverno. Esta zona húmida possui um dos maiores dormitórios de garças no Baixo Mondego: garça-boieira, garça-branca-pequena e garça-cinzenta. Uma terceira zona húmida é o Paul da Madriz (Fig. 2), este é relativamente restrito, possuindo cerca de 40 
hectares. À semelhança do que acontecera com o Paul do Taipal esta zona húmida foi ocupada com o cultivo do arroz.

No Baixo Mondego a paisagem é dominada pela planura do vale, pela água e pela geometria dos campos. Campos que foram objecto de uma importante reestruturaçáo fundiária estando as suas produções, hoje, fundamentalmente orientadas para o mercado. O cultivo do arroz que contribui para individualizar esta paisagem e a cultura das gentes no Baixo Mondego, designadamente a cultura gastronómica, na qual se inclui a doçaria conventual, confere particularismos à paisagem e um carácter mutante pois temporariamente o vale cobre-se de lâminas de água. Nas margens das linhas de água fileiras de árvores reforçam o desenho geométrico da paisagem quebrando a monotonia da topografia plana do vale. A vegetação riparia é essencial para aumentar os abrigos, permitindo a colonizaçáo ripícola das margens, margens que são pontuadas por importantes matas: a do Choupal, a da Geria, a de S. Silvestre e a de S. Martinho de Árvore (Fig. 2). Em 2008, em Abril, foi apresentado um Projecto de turismo sustentável para o maior rio português, intitulado Parque Patrimonial do Mondego, neste são propostas algumas rotas para a valorização do património do Baixo Mondego (Martins, 2008), algumas destas rotas apresentam-se na Figura 2, entre elas constam precisamente a Rota das Matas Ribeirinhas e a Rota do Arroz - que a Associação dos Agricultores do Vale do Mondego também tinha intenção de implementar (Vaquinhas \& Sousa, 2006) -, neste projecto esta última rota surge centrada em Maiorca e em Seiça (Fig. 2).

Para além da actividade agrícola no Baixo Mondego persistem ainda algumas importantes comunidades piscatórias não só no estuário do rio Mondego como na costa adjacente. Segundo dados do Núcleo de Pescas da Direcção Regional de Agricultura e Pescas do Centro DRAPCentro, em Abril de 2008, a comunidade da Ereira Montemor, com uma grande tradição ribeirinha, registava 21 unidades de pesca e 29 pessoas, cerca de 1.4 pessoas por unidade, trata-se de uma pequena comunidade que centra a sua actividade na pesca de rio que importa preservar e valorizar. Se esta análise ilustra a expressão profissional da actividade piscatória, não menos relevante é a pesca lúdica que se pratica nas margens das linhas de água do Baixo Mondego, bem como na costa. Apresentando o rio e os seus afluentes um importante potencial neste domínio, designadamente para competições desportivas.

A salicultura é uma actividade que se encontra em franca regressão. Se em 2003, de acordo com as Estatísticas da Pesca do Instituto Nacional de Estatística, existiam 37 Salinas, representando as salinas da Figueira da Foz cerca de 40\% das salinas de Portugal (39.8\%) a ocupar uma extensão de 95 hectares, com uma produção de sal de 1893 toneladas, cerca de $2,2 \%$ da produção nacional, em 2008 esses valores foram de 14 salinas, 28 hectares e apenas 687 toneladas de produçáo de sal, o que representava nesse ano cerca de um quarto $(25,4 \%)$ das salinas existentes em Portugal, mas apenas cerca de $1 \%$ da produção nacional de sal. As marachas, pequenos muros divisórios dos talhóes de salinas, são um dos elementos que marca esta paisagem e que lhe confere uma geometria muito própria, hoje, já não se observa o bulício dos marnotos, que a animavam, mas há a preocupação de preservação desta actividade num pequeno núcleo museológico, o Museu do Sal, criado em 2007. Uma exposição permanente e percursos pedestre ou de barco, numa Rota das Salinas (Fig. 2) foram as estratégias localmente encontradas para conservar a memória de uma actividade que diferenciava e que secularmente projectava a cidade e o 
território e que se reveste de extrema importância para a preservação do ecossistema estuarino, onde crescem em número as exploraçóes de aquacultura.

Há alguns investimentos que têm sido estruturantes para valorizar os ambientes aquáticos no Baixo Mondego. As intervençôes no âmbito do programa Polis na cidade de Coimbra, o Museu da Água de Coimbra (Fig. 2), localizado na margem direita na antiga Estação de Captação de Água, no Parque Manuel Braga, e na margem esquerda o Centro Náutico do Parque Verde (Fig. 2), que tem uma grande importância, pois é essencial que existam nas margens equipamentos de apoio às actividades náuticas, que suportem não só a sua prática por lazer como promovam formação, treino, estágios e competiçóes regionais, nacionais e internacionais. Também neste contexto a pista do Centro de Alto Rendimento de Montemor-o-Velho (Fig. 2) que irá acolher o Campeonato da Europa de Remo de 2010, que decorrerá no mês de Setembro, e que envolverá cerca de 500 atletas, desenvolve desde Maio de 2009, por Declaração de Utilidade Pública, a expropriação de alguns terrenos agrícolas para a ampliaçáo da pista de remo/centro náutico, classe $\mathrm{A}$, projectado para aquela vila marginal ao Mondego, o que significa que pode receber não só o Campeonato Europeu, como o Campeonato do Mundo e provas de Jogos Olímpicos. A esta oferta soma-se o porto de recreio da Figueira da Foz (Fig. 2). Neste sentido as estratégias para o Baixo Mondego devem também passar por criar equipamentos que apoiem as actividades aquáticas, o lazer e o turismo náutico, promovendo eventos desportivos a diferentes escalas, regionais, nacionais e internacionais.

\section{CONCLUSÃO}

Hoje, reconfiguram-se socialmente as utilizaçóes dos planos de água, redescobre-se o seu valor paisagístico, procuram ajustar-se as suas potencialidades às novas procuras sociais, designadamente, às actividades de recreação associadas ao lazer e ao turismo.

Portugal apresenta características naturais que permitem viabilizar um conjunto de actividades económicas, designadamente de animaçáo turística, em torno dos ambientes aquáticos, marítimos e não marítimos. O rio Mondego, o maior rio português, e os seus tributários, desempenham neste contexto um papel extremamente importante no Centro de Portugal, carecendo a oferta de ser promovida de forma integrada, designadamente em termos de lazer e turismo náuticos, com a criaçáo de produtos oferecidos no mercado local e internacional.

As freguesias confinantes/ribeirinhas do rio Mondego no seu baixo vale são espaços privilegiados para uma intervenção estratégica que preserve, valorize e aproveite o rio Mondego e as suas margens. É essencial que se projecte uma valorizaçáo do rio Mondego de âmbito interterritorial, intermunicipal, interinstitucional e interassociativo, que se constituam redes, que se estabeleçam parcerias e que os actores públicos e privados, locais e regionais, se envolvam na procura de uma gestão territorial equilibrada, sustentável e complementar, que se integre num processo de ordenamento e numa estratégia de desenvolvimento no sentido de fazer com que o rio integre o espaço vivido, no quotidiano, pela população residente, afirmando-se o seu potencial não só em termos de lazer como do turismo regional, nacional e internacional. É fundamental (re)criar de forma criativa uma aproximação da população ao rio Mondego, partindo de uma relação próxima, que é secular. E, com base neste princípio, valorizar os planos de água que existem neste ter- 
ritório e os lugares e espaços ribeirinhos. Tudo isto deve pressupor uma intervenção participada.

Nas margens a localização de equipamentos que suportem actividades de lazer e de turismo designadamente de turismo cultural, de turismo natureza, de turismo activo e de turismo aventura, complementar a outros turismos, e de infra-estruturas que promovam estes espaços é essencial, devendo haver uma selectividade no conteúdo das mesmas e na sua implantação territorial. É fundamental melhorar as condições para a pesca e a prática de actividades desportivas em ambiente aquático, como o remo e a canoagem, que se reabilitem os miradouros, que se criem condições para a observação de aves, o birdwatching e o turismo ornitológico não estão convenientemente explorados neste território; que se valorizem em trechos de rio os percursos pedonais ribeirinhos, criando parques nas margens; que se recuperem alguns dos antigos portos que foram importantes na navegação fluvial, podendo estes ser pontos estratégicos para a localizaçáo de bares e/ou de restaurantes que promovam a gastronomia local; que se intervenha nas praias fluviais existentes e se criem outras. Importante é igualmente a criaçáo de rotas temáticas que se afirmem verdadeiramente na promoção do território integrando os vários recursos patrimoniais, que se preservem as actividades tradicionais que criam emprego e que ainda dáo significado económico ao território.

Com uma dimensão geográfica interterritorial e um valor patrimonial local, regional e, em última instância, global, um dos maiores desafios que se colocam ao poder local é a gestão sustentável e a valorização destes ambientes aquáticos.

\section{REFERÊNCIAS BIBLIOGRÁFICAS}

Breil, Pascal; Marsalek, Jiri; Wagner, Iwona \& Dogse, Peter 2008, 'Introduction to urban aquatic habitats management' in Aquatic habitats in sustainable urban water management Iwona Wagner; Jiri Marsalek \& Pascal Breil, (eds), United Nations Educational, Scientific and Cultural Organization (UNESCO), Urban Water Series, 4, Taylor \& Francis, Paris, pp. 1-8.

Caldas, João Castro 2006, 'Água e desenvolvimento. Os territórios de Alqueva' in Desenvolvimento e território: Espaços rurais pós-agrícolas e novos lugaresde turismo e lazer Homenagem à professora Doutora Carminda Cavaco, Maria Lucinda Fonseca (coord.), Centro de Estudos Geográficos da Universidade de Lisboa, Lisboa, pp. 153-170.

Day, Elizabeth; Braioni, Giovanna \& Tezer, Azime 2008, 'Integrating aquatic habitat management into urban planning' in Aquatic habitats in sustainable urban water managemen, Iwona Wagner; Jiri Marsalek \& Pascal Breil (eds), United Nations Educational, Scientific and Cultural Organization (UNESCO), Urban Water Series, 4, Taylor \& Francis, Paris, pp. 107-127.

Erfurt-Cooper, P. 2009, 'European waterways as a source of leisure and recreation' in River Tourism, Bruce Prideaux \& Malcolm Cooper (ed.), Cabi, Oxfordshire, pp. 95-116.

Estatísticas da Pesca 2003 (2004), Instituto Nacional de Estatística, Lisboa.

Estatísticas da Pesca 2008 (2009), Instituto Nacional de Estatística, Lisboa.

Inskeep, Edward 1991, Tourism planning: an integrated and sustainable development approach, Van Nostrand Reinhold, New York.

Jennings, Gayle 2007, Water-Based Tourism, Sport, Leisure, and Recreation Experiences, Butterworth-Heinemann, Elsevier, Oxford.

Jones, Andrew L. 2007, 'On the water's edge: developing cultural regeneration paradigms for urban waterfronts' in Tourism, Culture and Regeneration, Melanie K. Smith, pp. 143-150.

Marshall, Richard 2001, 'Contemporary urban space-making at the water's edge' in Waterfronts in post-industrial cities, Richard Marshall (Ed.), Spon Press, Londres.

Martins, Luís Saldanha 2004, Espaços de lazer e de turismo no noroeste de Portugal, Ediçóes Afrontamento, Porto.

Martins, Nuno (coord.) 2008, Parque Patrimonial do Mondego projecto de turismo sustentável para o maior rio português, Museu da Água de Coimbra, Coimbra. 
Mauch, Christof \& Zeller, Thomas (eds) 2008, 'Rivers in history and historiography' in Rivers in history: perspectives in Europe and North America, University of Pittsburgh Press, Pittsburgh, pp. 1-10.

Ministério da Agricultura do Desenvolvimento Rural de das Pescas 2009, Pescas e aquicultura na Regiāo Centro: breve caracterização, Direcção Regional de Agricultura e Pescas do Centro. Consultado a 10 de Novembro de 2009 http://www.drapc.min-agricultura.pt/base/documentos/brochura_pescas_vf.pdf

Ministério da Economia e da Inovaçáo 2007, Plano Estratégico Nacional do Turismo PENT. Para o Desenvolvimento do Turismo em Portugal, Lisboa.

Prideaux, B., Timothy, D. J. \& Cooper, M. 2009, 'Introducing river tourism: physical, ecological and human aspects' in River Tourism, Bruce Prideaux \& Malcolm Cooper (ed.), Cabi, Oxfordshire, pp. 1-22.

Rebelo, Fernando; Cunha, Lúcio \& Almeida, A. Campar de (1990) 'Contribuição da Geografia Física para a inventariação das potencialidades turísticas do Baixo Mondego’, Cadernos de Geografia, 9, pp. 3-34.

Santos, Norberto Pinto dos \& Gama, António coord. 2008, 'Prefácio' in Lazer: da Libertação do tempo à conquista das práticas. Imprensa da Universidade de Coimbra, Coimbra.

Saraiva, Maria da Graça Amaral Neto 1999, O rio como paisagem: gestão de corredores fluviais no quadro do ordenamento do território, Fundação Calouste Gulbenkian e Fundação para a Ciência e Tecnologia, Lisboa.

Simões, José Manuel; Vale, Mário 2002, 'Valorizar e fruir o Tejo: uma aposta estratégica da região de Lisboa e Vale do Tejo', Sociedade e Território, 33, pp. 108-122.

Swarbrooke, John; Beard, Colin; Leckie, Suzanne \& Pomfret, Gill 2003, Adventure Tourism, ButterworthHeinemann, Oxford.

Vaquinhas, Irene e Sousa, Dina de 2006, Saberes e sabores do arroz carolino do Baixo Mondego, Associação dos Agricultores do Vale do Mondego, Coimbra.

Williams, Stephen 2009, Tourism Geography: a new synthesis, Routledge, London. 